\title{
Literatura y Movimiento Obrero en Portugal: la cultura política del socialismo en su teatro
}

\author{
Beatriz Peralta García \\ Universidad de Oviedo

\section{Literature and Labor Movement in Portugal: the Socialist Political Culture through its Theatre}

\begin{abstract}
RESUMEN
Los historiadores contamos con escasos recursos a la hora de estudiar el Movimiento Obrero en Portugal. Por esta razón la literatura se ha convertido en una de las fuentes más valiosas de las que disponemos para elaborar cualquier investigación sobre este tema. En este artículo intentamos estudiar la cultura obrera y la cultura política del socialismo portugués a través del análisis de las obras de teatro escritas por militantes socialistas y representadas para un público formado por la clase obrera portuguesa. Con este ejemplo, también queremos aportar algunas directrices metodológicas sobre el uso de este tipo de literatura como fuente para la historia socio-cultural.

PALABRAS CLAVE: Teatro, Literatura, Movimiento Obrero, Socialismo, Portugal, Historia Contemporánea
\end{abstract}

\begin{abstract}
Historians are short of means to the study of the Labor Movement in Portugal. Because of this, literature became one of the most valuable sources we have to do any research about on this matter. In this paper we try to study the Portuguese Working-Class Culture and the Socialist Political Culture through the analysis of the theatre plays written by socialist authors and performed for a working-class audience. With this example, we also want to provide some methodological instructions for the use of this kind of literature as a source for Cultural and Social History.
\end{abstract}

KEY WORDS:

Theatre, Literature, Labor Movement, Socialism, Portugal, Contemporary History

\section{EL SOCIALISMO PORTUGUÉS Y EL TEATRO}

La preocupación de las agrupaciones obreras europeas por el teatro data de finales del siglo XIX, al compás del debate surgido entre los intelectuales desde la segunda mitad de la centuria acerca de la literatura y el arte en general, que co- 
mienza a ser concebido a partir de entonces con un sentido utilitarista ${ }^{1}$. Ni Marx ni Engels teorizaron nunca sobre el teatro y apenas utilizaron el arte como un instrumento más de análisis en su crítica a la sociedad capitalista ${ }^{2}$. Por su parte, el arte escénico, con su particularidad de combinar espectáculo y enseñanza, sí llamó la atención de los anarquistas, que muy pronto elaboraron las bases de lo que debía ser una «dramaturgia obrera» ${ }^{3}$. Los socialistas se sumaron a este interés casi desde los inicios de su constitución como agrupación política organizada porque como denunciaría un militante de base en 1918 en las páginas de O Combate, el órgano oficial del Partido Socialista Português, el uso de otros instrumentos habitualmente presentes en las reuniones de las Casas del Pueblo, como los periódicos y las conferencias, limitaba la difusión del pensamiento socialista por sus exigencias formativas frente al teatro y las asociaciones recreativas, de ordinario mucho más populares:

«A imprensa tem valor só para os adultos que sabem ler. À tribuna só sobe quem tem no espirito enraizado aquele ideal sublime. Ao teatro, vão os homens e as mulheres, as crianças de todas as idades. Às sociedades de recreios, vai toda a engranagem social ${ }^{4}$.

El primero en darse cuenta de su potencial divulgador fue Manuel Luís de Figueiredo, tipógrafo, periodista, dramaturgo y principal animador de la corriente posibilista del entonces Partido dos Operários Socialistas que, según una de las tendencias dentro del género en la época, comienza a escribir dramas históricos: $A$ Última Favorita, Dramas da Realeza, Fidalgos e Populares, O Canalha y, sobre todo, Os Jesuítas, representado el 20 de febrero de 1881 con el objetivo declarado de servir a la difusión del pensamiento socialista y de los principios «sacrosantos» de libertad e igualdad ${ }^{5}$, una iniciativa con la que el autor intentaba contribuir al mismo tiempo a la revitalización del anquilosado teatro portugués. Es también por estos años cuando se funda una de las primeras agrupaciones teatrales obreras, el Grupo Dramático Socialista, a instancias de los seguidores de Azedo Greco, que junto a las obras de Manuel Luís de Figueiredo organizará su repertorio en torno al teatro social de actualidad. Surge entonces la necesidad de crear obras específicamente socialistas, una idea que José Martins Santareno traslada a un joven mi-

1 Entre otros un precursor del socialismo en Portugal como VIEIRA, Custodio José, «A utilidade na litteratura», A Península, tomo I, no 15, Abril 23, 1852, pp. 175-178; también PINHEIRO CHAGAS, Ensaios Críticos, Porto, Em casa da Viúva Moré —editora, 1866; FERREIRA J. M. Andrade, Litteratura, Música e Bellas-Artes, Lisboa, Typographia de J. G. de Sousa Neves, 1872; LATINO COELHO, Arte e Natureza, Lisboa, Empresa Literária Fluminense, 1923.

2 MARX, K., y ENGELS, F., Cuestiones de arte y literatura, Barcelona, Península, 1975.

3 LIVTAK, Lily, España, 1900. Modernismo, anarquismo y fin de siglo, Barcelona, Anthropos, 1990; Musa Libertaria. Arte, literatura y vida cultural del anarquismo español 1880-1913, Barcelona, Antoni Bosch, 1981; RUBIO JIMÉNEZ, Jesús, Ideología y teatro en España, 1890-1900, Zaragoza, Departamento de Literatura Española de la Universidad de Zaragoza, Libros Pórtico, 1982, pp. 109-131.

4 LOPES, Luís, «Racional Propaganda Social», O Combate, Lisboa, no 80, 2 de junio de 1918.

5 FIGUEIREDO, Manuel Luís de, «Antes do mais...», Os Jesuitas, drama original português, em 3 actos, Lisboa, Agencia Teatral, Biblioteca Progresso Teatral, 1883, p. 4. 
litante, Ernesto da Silva, para que componga un texto con la finalidad de ser representado durante la celebración del $1^{\circ}$ de mayo de 1895, ocasión que serviría también para recuperar el Grupo Dramático Socialista. Y, en efecto, tras O Capita ${ }^{6}$ (drama en cuatro actos, 1896), que así se titula la obra, el autor escribiría en años sucesivos Os que Trabalham ${ }^{7}$ (drama en cuatro actos, 1896), A Vítima (1898), Nova Aurora ${ }^{8}$ (Apropósito dramático en un acto y tres cuadros, 1900), Vencidos ${ }^{9}$ (drama en cuatro actos, 1902), Em Ruinas ${ }^{10}$ (pieza en tres actos, 1903) y Honestos (pieza en tres actos, s.d.), con el aplauso de la crítica y el desagrado de las autoridades políticas que impidieron la representación de $A$ Vítima en el teatro de D. Maria II a instancias de la fiscalía ${ }^{11}$. Es también a Ernesto da Silva a quien debemos el único texto programático sobre el teatro como un instrumento de difusión del pensamiento socialista en Portugal. Se titula Teatro Livre e Arte Social' ${ }^{2}$ y recoge los postulados básicos de una conferencia que su autor pronunciaría el 14 de diciembre de 1902 en el Ateneo Comercial de Lisboa. La iniciativa corría a cargo de los promotores del Teatro Livre, una sociedad creada a semejanza del Théâtre Livre (1887-1894) de Antoine en Francia, que aspiraba a renovar el teatro desde el punto de vista estético. Al ciclo de conferencias se sumaron destacados intelectuales como Teófilo Braga, el encargado de inaugurarlo, y Heliodoro Salgado, que compartió con Ernesto da Silva el título de su disertación, Teatro Livre e Arte Social, donde abogaba por un teatro de carácter pedagógico ${ }^{13}$. Ernesto da Silva, por su parte, siguiendo las reflexiones de Antero de Quental en Causas da Decadência dos Povos Peninsulares (1871), nuevamente en boga tras la crisis del UItimátum de 1890, entendía que el país sufría del déficit educativo característico de naciones decadentes o tiranizadas lo que, traducido al teatro, se concretaba en una corrupción moral y estética producto a su vez del despotismo económico de los empresarios al que no eran ajenos los propios autores. Su regeneración no vendría, por lo tanto, ni de las instituciones privadas ni de las públicas, como el Estado, sino de la iniciativa individual, de una elite espiritual «destinada á aggregação progresiva dos que uma vez acordados para a verdade, n'ella queriam ingresar trazendo fé para vencer e coragem para luctar ${ }^{14}$. No obstante, este razonamiento podía llevar a crear obras con un excesivo sesgo religioso que era necesario evitar. Ernesto da Silva proponía entonces aprovechar géneros como el drama social, la comedia de situación y el drama histórico, muy apreciados por el público, aunque dotándolos de un contenido moral ${ }^{15}$. Infelizmente, la prematura muerte del autor,

${ }^{6}$ Antes de su publicación fue representado en el Teatro do Principe Real en 1895. SILVA, António Ernesto da, O Capital. Drama em 4 actos, Lisboa, Typografia do Instituto de Artes Graphicas, 1896.

7 También representado en el Teatro do Principe Real en 1896.

${ }^{8}$ Fue representado con motivo del $1^{\circ}$ de mayo de 1900 en el Teatro do Principe Real.

${ }^{9}$ Se representó en el Teatro do Gymnasio en 1902.

10 SILVA, António Ernesto da, Em Ruinas, Lisboa, Biblioteca da Educação Nova ed., 1903.

${ }^{11}$ SOUSA BASTOS, Carteira do Artista. (Apontamentos para a historia do Teatro Portuguez e Brasileiro), Lisboa, ed. de José Bastos, 1898, p. 480.

12 Vid. SILVA, António Ernesto da, Teatro Livre e Arte Social, Lisboa, Tipografia do Comercio, 1902.

13 «Teatro Livre e Arte Social», O Mundo, Lisboa, 3 de febrero de 1903.

${ }^{14}$ SILVA, António Ernesto da, Teatro Livre e Arte Social, op. cit., p. 9.

15 Ídem, pp. 12-13. 
acaecida solo algunos meses después (25 de abril de 1903), impediría la concretización de su programa y el olvido de sus textos teatrales ${ }^{16}$, pues únicamente sabemos de la publicación efectiva de dos de ellos: O Capital, que inauguraba una recién creada "Biblioteca Socialista» y había sido editado por la tipografía del Instituto Geral das Artes Graficas y, Em Ruinas, publicado en 1903 por la Biblioteca da Educação Nova.

A partir de 1895, y coincidiendo con un momento de mayor control del movimiento obrero portugués, los socialistas irán poco a poco perfilando sus instrumentos de agitación social y de difusión doctrinaria. En la IIª Conferência Nacional Socialista que se reúne ese año en Tomar entre los días 14 a 16 de octubre no se alude aún al teatro pero sí se insiste en la necesidad de instruir a los niños y trabajadores creando escuelas y bibliotecas, además de proceder a una amplia labor propagandística en las asociaciones obreras ${ }^{17}$. La dificultad tanto para crear textos dramáticos como para organizar agrupaciones teatrales sigue de cerca los apuros del Partido Socialista por consolidarse como referente dentro del Movimiento Obrero organizado. Tras los vaivenes sufridos por el Grupo Dramático Socialista de Lisboa y el que funciona en Oporto con idéntico nombre ${ }^{18}$ a finales del siglo XIX surgen iniciativas como la desarrollada por José Fontana en Covilhã con el Grupo Dramático José Fontana ${ }^{19}$ o el Grupo de Teatro Dramático Actor Santos Junior, organizado por este conocido intérprete vinculado al Partido Socialista, que desenvuelve una limitada actividad en Lisboa ${ }^{20}$.

En 1913, ya proclamada la República en Portugal (5 de octubre de 1910), los socialistas comienzan a apostar decididamente por el teatro integrando a esta agrupación dramática definitivamente entre sus filas el 13 de julio de ese año. Raul Castela asume la dirección y en octubre se programa un ciclo de conferencias entre las que destaca la primera de ellas, proferida por Martins Santareno y titulada $A$ Propaganda Socialista no Palco ${ }^{21}$. De ahí que la primera referencia expresa a la utilización del teatro como un instrumento de difusión doctrinal aparezca en la sesión dedicada a la educación, desarrollada durante la celebración del IIo Congresso Socialista da Região Sul en octubre de 1914. En ella António Nunes da Silva ${ }^{22}$ retomará parte de los presupuestos de Ernesto da Silva sobre la utilización del arte en-

16 Sobre las obras de teatro socialistas vid. PERALTA GARCíA, Beatriz, La cultura obrera en Portugal. Teatro y socialismo durante la Primera República (1910-1926), Mérida, Junta de Extremadura, Gabinete de Iniciativas Transfronterizas, 2009, cap. 2. «Teatro e ideología: las dificultades para la organización de un arte escénico socialista», pp. 49-68.

17 NOGUEIRA, César, Resumo Histórico dos Congressos e Conferências do Partido Socialista (1876-1926), Lisboa, ed. da Revista Pensamento, 1932, pp. 36-43; FONSECA, Carlos da, História do Movimento Operário e das Ideias Socialistas em Portugal. Vol. IV. Greves e Agitações Operárias (1ª parte), Lisboa, Publicações Europa-América, s.d., pp. 253-272.

18 PERALTA GARCÍA, Beatriz, La cultura obrera en Portugal..., op. cit., p. 136.

19 Ídem, p. 122.

20 ídem, p. 123.

21 «Grupo Dramático Actor Santos Junior», O Socialista, Lisboa, no 450, 9 de octubre de 1913.

22 JUNIOR, António Nunes da Silva, «3ㅜㅡ These: A educação socialista, IIo Congresso Socialista da Região Sul», O Combate, Lisboa, no 16, 27 de noviembre de 1914. 
globándolos dentro de un plan de propaganda que incluía la adopción de cinco medidas: la introducción de fragmentos de doctrina socialista en la prensa partidaria, que formarían la base de una futura biblioteca socialista ${ }^{23}$; la constitución de «bibliotecas móviles»; la divulgación de poemas y obras de teatro para actores aficionados, componiendo un repertorio socialista; la organización de concursos de canciones populares; y, por último, la promoción de grupos excursionistas. En lo que atañe al teatro, Nunes da Silva focalizaba su atención en los obreros aficionados y, por lo tanto, en la formación de compañías de arte dramático. Además, recuperando las tesis de Ernesto da Silva, abogaba por la creación de un repertorio propio integrado por obras dramáticas y cómicas del teatro social, pero también por textos específicamente socialistas, creados por y para sus militantes. Hasta ese momento contaban únicamente con las obras antes mencionadas de Manuel Luís de Figueiredo y las del propio Ernesto da Silva y con un poema dramático de Joaquim dos Anjos titulado A Liberdade. Phantasia dramatica alusiva à implantação da República em Portugal, de 1911, pero eran poco reivindicativos en la medida en la que se escenificaban los problemas del Movimiento Obrero en general: las difíciles relaciones con la Iglesia y sus congregaciones - Os Jesuitas-, a los que la imaginería popular acusaba de robar niños, entre otros delitos; la explotación capitalista - O Capital-, el control de la maternidad mediante el aborto dada la falta de protección social -Em Ruinas-, o expresaban el apoyo de los socialistas al nuevo régimen político, como se desprende del poema de Joaquim dos Anjos $^{24}$. A la nómina hay que añadir otras dos obras de Ladislau Batalha: el drama $A$ Miséria ${ }^{25}$ y la comedia en un acto Consequencias de um-sim (1873), sobre las pretensiones amorosas de dos viejos sobre la joven Florinda ${ }^{26}$.

Lo que se pretende ahora es que dentro del propio texto dramático, los autores expongan no solo la denuncia de la sociedad capitalista sino lo que era más importante: que de manera inequívoca, sin dar lugar a dudas, se mostrase la doctrina específicamente socialista, en oposición incluso con otras propuestas obreras, como la defendida por los anarquistas, revelando al mismo tiempo el camino de la transformación social tal y como ellos la entendían.

Ya en 1905, Francisco Miguel Penha se había adelantado a este proyecto al escribir Um Sonho Socialista, que condensaba en cinco actos —únicamente se publicaron tres-y seis cuadros casi todas las preocupaciones y problemas de los obreros en estos años: la inseguridad del mundo laboral, la presión sexual sobre las mujeres por parte de los patronos, las tensiones entre anarquistas y socialistas

${ }^{23}$ La primitiva Biblioteca Socialista solo había podido publicar dos obras, ambas de Ernesto da Silva: el texto teatral antes mencionado, O Capital, y Proletarios e Burguezes, Lisboa, Instituto Geral das Artes Graphicas, 1893, y preveía la Azedo Gneco titulada Ideia Fundamental do Socialismo.

24 ANJOS, Joaquim dos, A Liberdade. Phantasia dramatica alusiva à implantação da República em Portugal, Lisboa, «A Editora», 1911.

25 SANTARENO, José Martins, «Teatro Social. (Continuação)», República Social, Porto, nº 41, 6 de diciembre de 1919.

26 BATALHA, Ladislau, Consequencias de um-sim, Lisboa, Editor J. J. Annaya, 1873. 
y la organización feliz de la sociedad socialista ${ }^{27}$. La obra permanecería inédita hasta 1920, cuando fue publicada por O Combatente, de Faro, en su sección dedicada al folletín, como también olvidado quedaría el drama de José Fontana da Silveira Honra e Trabalho $(1888)^{28}$, sólo conocido en la década de los años 30 . Los primeros textos siguieron de cerca el modelo del teatro social como Pedro, o Tecelão $0^{29}$ (1912-1913), de António Augusto da Silva, en la línea de otra obra célebre, Gaspar, o Serralheiro (drama en cuatro actos, 1877), de Eduardo Pedro Baptista Machado, de la que conocemos incluso su representación en Brasil a cargo de grupos anarquistas ${ }^{30}$, o Germinal. Comedia de propaganda social em um acto (19121913), de Zé de Pintéus, sobre las presiones a los obreros por el poder político y la Iglesia en tiempo de elecciones ${ }^{31}$, con claras alusiones a la novela de Zola. Ya Amor e Liberdade (1913), de Fontana da Silveira, aborda la recuperación social de una mujer prostituta gracias a la profesión del ideal socialista de sus hermanos ${ }^{32}$. En años posteriores se representarán $-\mathrm{y}$, en algunos casos, se publicarán como folletín o se editarán- el diálogo Francisco e João (1915), de António Nunes da Silva; A Filha do Burguês (1918), de José França; la tragicomedia Pai Tubarão, FiIho Cação ou como Filho de Peixe Não Sabe Nadar (1920), de Eduardo Metzner; O Selvagem (1923), de Manuel Gonçalves Reis; y, A Amante (1924), Amor Louco (s.d.) y $A$ Irmã Noviça (s.d), de António Augusto da Silva. Para el período comprendido entre el golpe de Estado de 28 de mayo de 1926 y la definitiva instauración del Estado Novo en 1933 tenemos noticia de las siguientes obras: Marcelino, o Pastor (1927) y Duas Uniões Vitoriosas (1931), de Jaime Ferreira Dias; Sacrificio de Irmã (1929), de Lopes Viana; O Engeitado (1929), de M. A. Silva Ferreira; A Última Noite Bourbonica em Espanha (1932) y Cancro Social (1932), de Pinto de Castelar; y la producción, no representada, de Eduardo Rocha: Na Vida (1931), A Grande Dor (1931), O Doutor Delegado (1932), A Grande Questão (1932) y Uma Mulher!... (1933) ${ }^{33}$.

27 PENHA, Francisco Miguel, «Folhetim de O Combatente. Um Sonho Socialista ou Conferencias criticas e instrutivas ao povo operario d'hoje, concatenadas em forma de drama", O Combatente, Faro, $\mathrm{n}^{\circ}$ 7, 29 de enero de 1920. El periódico publica un artículo del autor, firmado en la misma ciudad de Faro, el 15 de agosto de 1905, en el que cuenta el argumento de la obra.

28 SILVEIRA, José Fontana da, «Honra e Trabalho. Drama histórico e educativo em 1 acto, baseado na vida de Miguel Sedaine, eminente architecto francez», Encyclopedia das Famílias: Revista de Instrução e Recreio, Lisboa, Lucas \& Filho Editores, 1888, Nos 362-366.

${ }_{29}$ Un personaje secundario, con idéntico nombre y profesión, aparece por primera vez en O Capital, cit., de Ernesto da Silva.

30 Vid. PETERSEN, Silvia Regina Ferraz, «O anarquismo no Rio Grande do Sul na Primeira República», Revista do Instituto de Filosofia e Ciências Humanas da Universidade Federal do Rio Grande do Sul, UFRGS, Porto Alegre, RS, Brasil, 1991-1992, p. 137. Incluimos el texto de la obra en portugués en los apéndices de nuestra monografía PERALTA GARCíA, Beatriz, La cultura obrera en Portugal..., cit., pp. 240-286.

${ }_{31}$ Vid. texto en portugués en PERALTA GARCÍA, Beatriz, La cultura obrera en Portugal..., op. cit., pp. 161-167.

32 «Amor e Liberdade», A Batalha Socialista, Lisboa, no 15, 1 de noviembre de 1913.

33 Sobre la producción teatral socialista de este período vid. PERALTA GARCÍA, Beatriz, La cultura obrera en Portugal..., op. cit., pp. 49-68. 
Sin embargo, y pese al esfuerzo realizado por el grupo socialista por crear una dramaturgia propia, pronto se hizo patente la exigüidad de su repertorio, incapaz de atender la demanda de un público que buscaba ante todo divertirse cuando acudía a una celebración partidaria. Lo prueba el fracaso de la representación de $A$ Amante, una de las mejores obras socialistas tanto desde el punto de vista doctrinal como técnico, a pesar de la opinión francamente negativa de Martins Santareno que censuraba, precisamente, el privilegio dado por el autor al mensaje político en detrimento de la trama ${ }^{34}$. La respuesta de las agrupaciones teatrales fue acudir al teatro social decimonónico, un filón inagotable en cuanto a la producción de dramas de actualidad y comedias de costumbres con el que atender las necesidades lúdicas de los espectadores sin caer en la repetición.

\section{EL TEXTO TEATRAL COMO FUENTE}

Las fiestas partidarias son el elemento que justifica la puesta en escena de una obra de teatro ${ }^{35}$. El calendario integraba tres conmemoraciones fijas: la fundación del Partido Socialista Portugués el 10 de enero de 1875, la Comuna de París el 18 de marzo y el $1^{\circ}$ de mayo; las fiestas de beneficencia, por el contrario, se desarrollan a lo largo de todo el año sin una periodicidad establecida. Pensando en los asistentes al espectáculo los responsables de su organización procedían a una elaboración cuidadosa del programa previsto que incluía conferencias, actuaciones musicales y representación de obras teatrales. La elección de estas últimas dependía del carácter de la fiesta alternando, en cualquier caso, piezas dramáticas con otras cómicas.

La necesidad de difundir el ideal socialista obligó a los autores a abandonar el género histórico y los cuadros alegóricos y a optar, pragmáticamente, por el realismo y el costumbrismo literarios pues, como había advertido Ernesto da Silva, ofrecían un modelo temático y estético muy apreciado por el público. Los obreros debían reconocerse en escena no solo desde el punto de vista del contenido, esto es, en lo que les preocupaba o en las actitudes que debían observar frente a sus problemas, sino también en su vida cotidiana, en la recreación de su ámbito privado - la casa, con sus enseres domésticos - y público - la fábrica y los espacios de sociabilidad-; o, incluso, en el vestuario y el lenguaje, que debía ser cuidado y evitando siempre un uso indecoroso ${ }^{36}$. Por ello, un elemento a tener en cuenta cuando nos enfrentamos al análisis de este tipo de teatro es el material objeto de nuestro estudio, un texto que además de ser una construcción del autor res-

34 Ídem, pp. 63-64. Realizamos un análisis más detallado de ella en PERALTA GARCíA, Beatriz, «Retórica e ideología en el teatro socialista portugués de la Primeira República», LÓPEZ EIRE, A., LABIANO ILUNDAIN, J. M., y SEOANE PARDO, A. (eds.), Retórica, Política e Ideología. Desde la antigüedad hasta nuestros días, vol. II. Desde la Modernidad hasta nuestros días, Salamanca, Asociación Española de Estudios sobre Lengua, Pensamiento y Cultura Clásica, 1998, pp. 295-301.

35 PERALTA GARCÍA, Beatriz, La cultura obrera en Portugal..., op. cit., pp. 143-150.

36 Ídem, p. 26, passim. 
ponde a la idea del «teatro de tesis», de exposición de una ideología, de modo que el desarrollo de la trama de ficción se verá frecuentemente interrumpido para dar lugar a la exposición doctrinal. Por lo tanto, habremos de tener presentes conceptos propios del ámbito de la teoría de la literatura que distingue entre obra dramática, una creación del lenguaje puramente literaria, y obra teatral, un texto concebido para ser representado ${ }^{37}$. En este sentido, el teatro obrero es sobre todo una obra pensada para ser escenificada y, por lo tanto, en su estudio intervienen elementos específicos de la crítica textual: estructura, personajes, variables de espacio y tiempo, pero también -y esto es lo más importante- el escenario y la puesta en escena, en la que participan actores, vestuario, iluminación, música y, sobre todo, el público al que estaba destinada, un público obrero que asiste al espectáculo en espacios habilitados para tal fin, sobre todo en las Casas del Pueblo o en teatros alquilados ${ }^{38}$.

La combinación del elemento doctrinal con el estrictamente teatral aporta una información múltiple y variada sobre el carácter pedagógico atribuido al teatro y, en otro orden, nos orienta al respecto de las preocupaciones sociales del Movimiento Obrero. También revela datos en el ámbito de la sociabilidad o sobre costumbres de la vida cotidiana de difícil rastreo en las fuentes documentales clásicas. Reconstruir todos estos aspectos es una tarea ardua y compleja, de especial dificultad en lo que atañe a la historia del Partido Socialista Portugués, porque como ya hemos comentado en otras ocasiones ${ }^{39}$ hay que subrayar la escasez de sus fuentes documentales conservadas, que obliga al investigador a un ejercicio de imaginación en la búsqueda de instrumentos alternativos de análisis que arrojen luz sobre los interrogantes planteados. La fotografía ${ }^{40}$, el cine ${ }^{41}$, la música ${ }^{42}$ o la literatura, sobre la que se ha venido en llamar la atención en repetidas ocasiones ${ }^{43}$ y cada

${ }^{37}$ VILLEGAS, Juan, Interpretación y análisis del texto dramático, Ottawa, Ontario, Girol Books, Inc., 1982, pp. 9-10.

${ }^{38}$ Vid. a este respecto PERALTA GARCÍA, Beatriz, La cultura obrera en Portugal..., op. cit., pp. 140143.

39 Vid. PERALTA GARCÍA, Beatriz, «El teatro socialista como fuente para la historia de la cultura obrera en Portugal», Revista de Historiografía, Instituto de Historiografía Julio Caro Baroja, Universidad Carlos III de Madrid, № 2, II (1/2005), Madrid, 2005, pp. 136-142; también La cultura obrera en Portugal..., op. cit., p. 11 y ss.

40 BRAOJOS GARRIDO, Alfonso, «La fotografía de prensa como fuente histórica. Un modelo de referencia: la aportación sevillana», Ayer, no 24, 1996, pp. 69-90.

${ }^{41}$ AMADOR CARRETERO, Pilar, «El cine como documento social: una propuesta de análisis», Ayer, no 24, 1996, pp. 113-145.

42 CASTRO, Demetrio, «Tipos y aires. Imágenes de lo español en la zarzuela de mediados del siglo XIX», Ayer, no 72 , 2008, pp. 57-82.

${ }^{43}$ Desde los textos clásicos: JOVER ZAMORA, J. M., «De la literatura como fuente histórica», Boletín de la Real Academia de la Historia, Tomo CLXXXIX, Cuaderno 1, enero-abril, 1992; SECO SERRANO, Carlos, "La construcción de la historia objetiva: las fuentes; ayer y hoy», en ALMUIÑA, Celso, et alii, Cultura y civilizaciones. III Congreso de la Asociación de Historia Contemporánea, Valladolid, Universidad de Valladolid, 1998, a la actualidad en aportaciones como: NIETO FERRANDO, J. J., «Literatura e Historia. De la "función social" de la literatura a su futuro como "documento histórico" a partir de Juan Goytisolo", Ayer, no 59, 2005; PERALTA GARCÍA, Beatriz, «El teatro socialista como fuente...», cit.; FUSTER GARCÍA, Francisco, «La novela como fuente para la Historia Contemporánea: El árbol de la ciencia de Pío Baroja y la crisis de fin de siglo en España», en este mismo Dossier. 
vez más utilizada en el ámbito de la investigación científica ${ }^{44}$, son sólo algunos de los nuevos dominios sobre los que los especialistas han comenzado a focalizar su atención. En nuestro caso, a la información aportada por la prensa partidaria hay que añadir la que es posible inferir a través de sus manifestaciones culturales, desde las artes plásticas a la literatura: novelas ${ }^{45}$, poemas ${ }^{46}$, y teatro, no solo como temas de estudio en sí mismos, sino como fuentes para el conocimiento de esta agrupación obrera. No se trata, sin embargo, de centrar solo la mirada sobre el tema propuesto por el autor sino también en el tratamiento dado, observando lo hasta ahora considerado anecdótico o banal, o subordinado exclusivamente a la trama de ficción, ya que nada es casual sino que responde a una intencionalidad premeditada.

\subsection{La elección del género: entre el drama y la comedia}

A la hora de escribir una obra teatral los intelectuales obreros se decantaron por el drama, entendido aquí como sinónimo de «tragedia» según la definición de la Poética ${ }^{47}$, y, por lo tanto, incluyendo dentro del género estructuras como el monólogo y el diálogo. Todas las obras anteriormente reseñadas se ajustan a este arquetipo con excepción de la comedia ${ }^{48}$ de Ladislau Batalha, por carecer de mensaje doctrinal. La adopción de la variante híbrida, esto es, la tragicomedia, resulta de escaso interés para los autores ya que solo podemos documentar una obra con estas características: Pai Tubarão, Filho Cação ou como Filho de Peixe Não Sabe Nadar... Tragedia cómica em familia publicada por Espartaco (Eduardo Metzner) en O Combate en 1920. Cuenta la escisión del Movimiento Obrero tras la

44 DE LA FUENTE MONGE, Gregorio, «El teatro republicano de la Gloriosa», Ayer, n 72, 2008, pp. 83-119; GARCÍA, Hugo, «Relatos para una guerra. Terror, testimonio y literatura en la España nacional», Ayer, n 76, 2009, pp. 143-176; PERALTA GARCÍA, Beatriz, «La imagen de D. Pedro y D. Miguel en la novela histórica portuguesa del siglo XIX», Espacio, tiempo y forma. Revista de la Facultad de Geografía e Historia, Serie V, Historia Contemporánea, n 18, 2006, pp. 17-34; ídem, «La memoria de las invasiones francesas y la revolución liberal en la novela histórica peninsular del siglo XIX», Cuadernos del Minotauro, n ㄱ, 2006, pp. 101-112; ídem, «Mário o la historia bajo el disfraz de novela», FERNÁNDEZ GARCÍA, Ma Jesús, y OGANDO, lolanda (coords), Limite. Revista de Estudios Portugueses y de la Lusofonia. História na(s) literatura(s) em língua portuguesa, Volumen 2, Cáceres, Universidad de Extremadura, 2008, pp. 135-158; ídem, «Arnaldo Gama y la Guerra Peninsular en la novela histórica portuguesa», DIEGO, Emilio de (dir.), y MARTÍNEZ SANZ, José Luis (coord.), El comienzo de la Guerra de la Independencia, Madrid, Ed. Actas, 2009; ídem, «Traumas vividos y traumas contados. El impacto emocional de la guerra en la novela histórica del siglo XIX» (en prensa).

45 Prácticamente desconocida a falta de un estudio detallado apuntamos su presencia en la sección dedicada al folletín de los periódicos obreros en PERALTA GARCÍA, Beatriz, La cultura obrera en Portugal..., op. cit., pp. 79-81.

46 Le hemos dedicado nuestra atención en un breve artículo: PERALTA GARCÍA, Beatriz, "Poesía y política en la prensa obrera. Las "Carapuças d'O Socialista"», AA. VV., Relaciones lingüísticas y literarias entre Portugal y España desde inicios del siglo XIX hasta la actualidad, Salamanca, Universidad de Salamanca, 2007, pp. 269-279.

47 ARISTÓTELES, Poética [Introducción, traducción, notas y comentario de Antonio López Eire], Madrid, Ediciones Istmo, 2002, p. 45

48 Ídem, p. 43. 
Revolución Bolchevique y no deja de ser significativo que el hecho sea encarado al mismo tiempo como una tragedia no exenta de comicidad. El autor utiliza una metáfora familiar: la seducción que la vida fácil ejerce sobre los hijos a pesar de haber recibido una educación sensata por parte de sus progenitores ${ }^{49}$. La escasa atención dada a la comedia nos informa, a su vez, de la dimensión psicológica subyacente al tratamiento dado a ciertos temas, pues los socialistas llevaron a los escenarios piezas cómicas pero procedentes todas del teatro social, donde el elemento jocoso deriva mayoritariamente de las relaciones personales $\mathrm{y} / \mathrm{o}$ sentimentales y tiene por base el equívoco.

\subsection{Los temas: una radiografía de las preocupaciones sociales}

La mayoría de los textos teatrales escritos por los socialistas portugueses se organiza en torno a tres ejes temáticos: la denuncia de la sociedad capitalista, el diseño de la sociedad socialista y la exposición de valores morales ${ }^{50}$. La concretización de cada uno de ellos en diferentes subtemas nos permitirá conocer el mosaico de las preocupaciones y deseos del operariado de principios del siglo XX en Portugal, así como sus propuestas en cuanto a hábitos y actitudes cívicas de conducta, un aspecto al que los socialistas prestaron una particular atención intentando contrarrestar así la mala imagen que la burguesía transmitía de ellos y que el teatro también permite rastrear. Véase, por ejemplo, el siguiente monólogo tomado de $O$ Capital. En él Carlos Marques, hijo del propietario de la fábrica, es echado de su casa por su propio padre al conocer sus simpatías por las reivindicaciones de los obreros y el apoyo a la huelga que mantienen. Mirando al público, tal como indican las acotaciones, el personaje describe la sociedad capitalista:

«(...) Descerei á arena da lucta pela vida a degladiar-me com a instabilidade do salariato, retemperarei a alma no cruciante poema social en que ha escolhidos e réprobos... réprobos os que trabalham, escolhidos os que parasitam. Habitarei a cidade! Atravez as vidraças, contemplarei os replectos commensaes dos hotéis luxuosos, em salas guarnecidas de raros estofos; ouvirei no átrio as voluptuosas caricias da orchestra, embalando-lhes os gastos espíritos, em ondas de vaporosas phantasias... No portal, acoutada da chuva gélida, miúda, impertinente, verei a esquecida creancinha, cabellos esparsos ao vento frio; aljofrados de iriados glóbulos, sollicitando á ventura, surja quem compre uma innocencia que desabrochou prostituída... Flores fanadas, na impulsão do vicio que corroe a alma, verei as mulheres, em almoeda o corpo, condemnadas ao esterquilinio, victimas de eterno soffrer, porque um dia não tiveram pão!... risadas de salões, gemidos de mansardas, taças

\footnotetext{
${ }^{49}$ Puede consultarse el texto en portugués en PERALTA GARCíA, Beatriz, La cultura obrera en Portugal..., op. cit., pp. 168-173.

50 PERALTA GARCÍA, Beatriz, La cultura obrera en Portugal..., op. cit., pp. 88-91; SERRANO, Carlos, «Notas sobre el teatro obrero a finales del siglo XIX», AA.VV., El teatro menor en España, Madrid, Consejo Superior de Investigaciones Científicas, 1983, p. 270; BELLIDO NAVARRO, Pilar, Literatura e ideología en la prensa socialista (1885-1917), Sevilla, Alfar, 1993, p. 117.
} 
que scintillam, enxergas que apodrecem, sedas que rumorejam, farrapos que se esgarçam, em breve serei comvosco!... (...) ${ }^{51}$

En unas pocas frases Carlos muestra dos formas de vida completamente opuestas: la que disfrutan los sectores más acomodados de la sociedad y la de los sectores asalariados y económicamente inestables que asisten al espectáculo. Esta dicotomía es reforzada con la descripción de dos imágenes particularmente impactantes e indignantes: la miseria infantil y la prostitución femenina. En contrapartida, la sociedad socialista se presenta como un mundo feliz en el que reina la paz y la justicia social:

"Cada localidade teria as suas classes segundo as suas industrias e cada classe as suas oficinas sociais segundo as necessidades de produção!

A instrução geral obrigatória seria então o ensino elementar, mas experimental, de todas as sciencias conhecidas, ministrada na propia oficina de cada classe, e a especial, - a continuação de quasquer sciencias ou artes, segundo a vocação provada do interessado, ou a necessidade d'estas especialidades! (Mais alguns passos em silencio)

Este regimen poder-se-hia estender a toda a Humanidade, em que cada classe prestaria os seus serviços por valores correspondentes ás suas necessidades e os homens seriam aproveitados segundo a sua competencia!

(...) Vae-te sonho chimerico, não me faças mais infeliz, que a Humanidade não merece tanto! »52

La denuncia de la sociedad capitalista alcanza tres ámbitos: la política, la religión y la familia. Dentro de la crítica política los socialistas atacaron la actuación de los tres poderes del Estado y, en particular, la del judicial. Como apuntábamos antes, es en este espinoso terreno donde encontramos la especialización genológica a la que hacíamos referencia: los socialistas optaron por el drama para denunciar un ejercicio parcial del sistema judicial basado en la impunidad ante la ley de quienes se situaban más cerca de los órganos del poder, la existencia de lazos afectivos entre jueces y reos 0 , simplemente, de pertenencia a un mismo estrato social. Un ejemplo significativo de cómo se veía la actuación de los jueces y del fundamento del sistema de justicia nos lo proporciona el drama de Eduardo Torralba Beci traducido con el título $A$ Justiça. Tras recluir en la cárcel a un joven acusado de amenazas y agresión y dejar en libertad a un individuo detestable pero útil al poder político D. Clemente, el juez, explica:

51 SILVA, António Ernesto da, O Capital, op. cit., acto terceiro, scena, VII, p. 53.

52 PENHA, Francisco Miguel, Um Sonho Socialista, op. cit., terceiro acto, scena Ia. 
«D. Clemente -Ouça, bom homem: se a justiça se fosse a deixar conduzir pelas lamentações de outras pessoas de igual jaez, deixaria de cumprir a augusta missão que desempenha para se converter em instrumento de um montão de esfarrapados que satisfariam os seus ódios e as suas vinganças à sombra dela»53.

Sin embargo, para criticar al ejecutivo o al legislativo se inclinaron muchas veces por la comedia. Uno de los textos más divertidos que llevaron a los escenarios es As Rédeas do Governo, una comedia española en tres actos traducida al portugués ${ }^{54}$ por Luis Augusto Rebello da Silva y representada en el teatro de D.Maria II. Se trata de una sátira política al sistema de gobierno bajo Isabel II, personificada en $\mathrm{D}^{\mathbf{a}}$ Clara, y el ámbito doméstico de su casa, donde el poder se ejerce de forma despótica e irracional.

En el terreno de la religión las críticas se dirigen simultáneamente hacia la Iglesia como institución y sus pretensiones de control sobre el Movimiento Obrero portugués. Contrariamente a lo que pudiera parecer no existe un anticlericalismo exacerbado al margen de la imagen más o menos negativa que, puntualmente, se pueda transmitir de sacerdotes como el padre Le Roy de Os Jesuitas, el ladrón de la hija de Manuel, Beatriz, convertida ahora en un miembro de la aristocracia. Quizá el aspecto que suscitaba más recelo —y de más difícil rastreo documentalera la relación que, como hombres vulnerables a las pasiones sexuales, mantenían con las mujeres». De hecho, en no pocas ocasiones el acoso sexual procedía de ellos y las obras no dejaron de subrayar este aspecto:

«Abáde: Contemplando-a) - Como és tão linda e tão apetitosa, com essa indignação inútil!... Cada vez que agora me fálas mais bela mais sedutora te tornas!... Estamos sós! Aqui ninguem te vale! Pertences-me! Para que te indignas? Para que te recusas tão formalmente?... (aproxima se de Amelia e esta recúa até ao outro lado da cêna) - Esse teu olhar tão fascinador e agora tão cheio de vida, estonteiame!... Amélia, este sitio tão deserto e tão ameno parece que me foi dado por Deus para expandir e saciar o meu amor! Vá entrega-te aos meus braços! (avança sobre Amélia que foge para outro lado, fitando o abade como desafio) - Fogesme! recusas-te! e cada vez sinto lavrar dentro de mim, com um vigor forte, violento! todas as mais doces sensações do meu ser!... Oje quero que me ames! Oje quero possuirte!... Vamos, Amelia, aos meus braços, deusa querida dos meus sonhos d'amôr!... (corre sobre Amélia que vem ao seu encontro brandindo a tesoura e cravando-Ih'a no peito)»55

Finalmente, la familia es el tercero de los ejes temáticos más abordados dentro del teatro obrero. En el fragmento antes reproducido de la descripción de la sociedad capitalista trazada por Carlos Marques aparecen dos de los grupos sociales

53 TORRALBA BECI, Eduardo, A Justiça, Acto I, cena XIV.

54 REBELLO DA SILVA, Luiz Augusto, «Nota Bibliographica», Othello ou o Mouro de Veneza. As Redeas do Governo, Lisboa, Empreza da Historia de Portugal Sociedade Editora, 1907, p. 6.

55 SILVA, António Augusto da, Pedro, o Tecelão. Drama original em 3 actos, Porto, Imprensa Civilisação, en $A$ Luz do Operário, Porto, №s 499-527, 14 de abril de 1912 a 11 de mayo de 1913, acto 2º, terceira cena. 
más débiles y de mayor preocupación para los socialistas: los niños y las mujeres $^{56}$. En el primer caso, los socialistas denunciaron uno de los problemas más lacerantes, el abandono, porque significaba la exclusión casi definitiva de los individuos de la sociedad al llegar a la edad adulta. Privados de afecto, abocados a la miseria más absoluta, solían transmitir una imagen de degradación física y de repulsión, tal y como hace notar el protagonista del monólogo de Silva Ferreira O Engeitado:

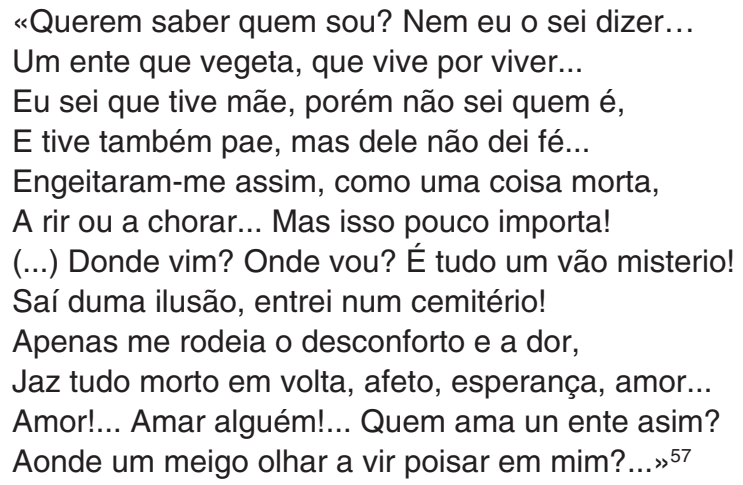

Junto al abandono infantil la prostitución femenina ${ }^{58}$ es otro de los temas que más preocupa a los socialistas. Así lo indica el conjunto de obras que lo tratan, bien como protagonista absoluta, bien de forma tangencial, del teatro social pero también en muchas de las obras que escribieron a lo largo de los años: Amor e Liberdade, Duas Uniões Vitoriosas, Pedro, o Tecelão, Na Vida, A Justiça, Marcelino, o Pastor, Sacrificio de Irmã y Cancro Social. Su lectura indica que los socialistas la contemplaban como un problema social y no veían a la prostituta como un ser marginal, según la imagen transmitida por las corrientes literarias realista y naturalista. Para el socialismo portugués, y al margen de su vinculación con el delicado tema del honor, la prostitución se relaciona con el acoso sexual, la violación y, en general, con la desprotección que las mujeres sufren cuando desaparece la cobertura social y económica que significa la existencia del cabeza de familia. Es esta la reflexión que Carlos Marques realiza ante los espectadores.

Ante tal rosario de problemas y preocupaciones los autores se vieron obligados - por su condición de dramaturgos, tanto como por la de socialistas-a

56 Sobre la imagen que de las mujeres se transmite en el teatro obrero socialista vid. nuestro artículo «Obreras, prostitutas y burguesas. La mujer en el teatro socialista portugués» (en prensa).

57 SILVA FERREIRA, «Teatro Social. O Engeitado. Monologo, por Silva Ferreira», Republica social, Porto, no 385 (2 $2^{\text {a }}$ serie), 13 de julio de 1920.

58 Sobre este tema vid. PERALTA GARCÍA, Beatriz, «La prostitución en el teatro socialista portugués de la Primera República (1910-1926)», LÓPEZ CRIADO, Fidel (Ed.), Wenceslao Fernández Flórez y su tiempo. Evasión y compromiso en la literatura española de la 1a mitad del siglo XX», A Coruña, Ayuntamiento de La Coruña/Concello de A Coruña, 2002, pp. 379-386. 
ofrecer un final esperanzador. Muchas obras tienen un doble desenlace feliz: en el desarrollo de la trama y también en su contenido doctrinal. En A Amante, del año 1924, Antonio Augusto da Silva construye una trama en torno a un matrimonio en plena crisis por las simpatías socialistas del marido, un abogado de renombre. El drama se desencadena cuando ante la imposibilidad de encontrar compresión en casa, pues la esposa se muestra abiertamente en contra de su ideología, este comienza una relación sentimental con una mujer obrera también casada. El clímax narrativo se alcanza cuando los personajes se ven enfrentados con su propia realidad. A partir de este momento el autor recompone cada una de las piezas del conflicto: los obreros ganan la huelga y el matrimonio sobrevive gracias a la aceptación de los ideales del marido por parte de la esposa y a la presencia de un elemento externo y trágico, la muerte de la heroína a manos de su marido, un hombre sin escrúpulos al que las acotaciones describen como «operario vadio, bebado e desordeiro» 59 .

Este aspecto nos permite abordar el tercer eje temático de las obras teatrales socialistas: el de la exposición de los valores de clase. Los textos divulgaron la necesidad de la educación y de la instrucción, además del amor al trabajo y la honradez en su desempeño, como rasgos diferenciales de la clase obrera, acompañados de la necesaria cohesión interna para defender sus intereses, cifrada en la solidaridad. Sin embargo, lo más significativo es que se esforzaron en fomentar también hábitos de conducta social que descendían a situaciones muy concretas de la vida cotidiana: frecuentar la asociación frente a la taberna, leer o asistir a sesiones públicas de lectura, y observar pulcritud e higiene en su aspecto físico. Como veremos, todos estos elementos aparecen regulados en las obras de teatro a través de las acotaciones.

\subsection{Los personajes masculinos y femeninos}

Los personajes masculinos y femeninos pueden aportar información sobre la organización de las agrupaciones teatrales. Según el número de mujeres que intervienen en una obra teatral es posible apuntar, por ejemplo, la presencia femenina y sus funciones dentro del Movimiento Obrero organizado, pero sobre todo, evaluar su nivel de compromiso en el ámbito de las propuestas lúdicas. Sabemos que este terreno está dominado mayoritariamente por hombres, sobre todo a través del deporte y, en concreto, del fútbol, y conocemos la formación de asociaciones deportivas vinculadas a la Federação Socialista dos Desportos Atléticos a partir de los años 20 y la aparición de los primeros periódicos ${ }^{60}$. La organización de

59 SILVA, António Augusto da, A Amante, Porto, Tipografia Sequeira, Limitada, 1924, 2ํacto, scena III, p. 24.

60 Vid. «Federação Socialista dos Desporto Atleticos», A Humanidade, Lisboa, nำ 3, 5 de febrero de 1922; A. F., «O Futebol», O Desporto Operario, Lisboa, no 2, 5 de noviembre de 1922; ídem, «Federação Socialista dos Desporto Atleticos», ibídem. 
grupos teatrales ${ }^{61}$ es, sin embargo, muy anterior. También aquí la presencia masculina parece ser mayoritaria, aunque tampoco puede afirmarse que las mujeres solo formasen parte de ellas de forma testimonial.

Ya desde el punto de vista textual conviene destacar la construcción dicotómica de los personajes en términos absolutos. No hay espacio para los matices. Como ya hemos dicho el mensaje debía ser claro, inequívoco, de modo que la oposición héroe/villano debía identificar bien quiénes son los buenos, los socialistas, y quiénes los malos, todos aquellos que, independientemente de su adscripción social, no lo son. En otras palabras, para la intelectualidad obrera la ideología socialista tiene una vocación interclasista a pesar de la tensión siempre latente con los sectores obreristas que se mostraban muy críticos con las pretendidas simpatías hacía el Movimiento Obrero de los miembros de la burguesía. Los personajes, por otra parte, aparecen habitualmente denominados con su nombre propio $^{62}$, indicando así proximidad o cercanía con el público, seguido de la designación "operario» de forma global para mostrar la ocupación del protagonista aunque a veces sí se concreta, como sucede en el caso de Pedro, tejedor, en la obra homónima, aunque se trata de una excepción. Las «profesiones de la burguesía»: policía, jueces, políticos, etc, suelen aparecen de forma secundaria, y cuando se elevan al plano principal de la acción el personaje es siempre el reverso del héroe obrero. Tampoco se concreta la edad de los personajes, que se dividen entre jóvenes o viejos, sin más indicaciones, ni el aspecto físico que estos deben tener en escena. La adjetivación es vaga, imprecisa, alternando de forma recurrente calificativos como «pobre» 0 «elegante», para aludir a las ropas o al peinado. Esta carencia de directrices escénicas tiene razón de ser en función del público al que se dirige, los obreros de forma general y no a agrupaciones laborales específicas, ni a segmentos de edad concretos, por lo que hemos de suponer que tanto el vestuario como la peluquería habrían de reproducir el propio de los asistentes al espectáculo.

Es más significativo el mundo de los valores morales. Como anotamos antes son las actitudes lo que verdaderamente importa y el conjunto de asociaciones que se establecen en la construcción de determinadas imágenes. Un ejemplo significativo lo encontramos en $A$ Amante y en las características atribuidas a los socialistas y a aquellos que no lo son. El segundo acto se desarrolla en medio

61 Sobre las agrupaciones teatrales de obreros aficionados vid. PERALTA GARCÍA, Beatriz, La cultura obrera en Portugal..., op. cit., pp. 121-139; ídem, «El teatro de aficionados: las agrupaciones teatrales socialistas de Oporto", en Profesor Basilio Losada: ensinar a pensar con liberdade y risco, Barcelona, Publicacions de la Universitat de Barcelona, 2000, pp. 577-581.

62 Sobre el personaje teatral vid. VILLEGAS, Juan, Interpretación y análisis..., op. cit., pp. 78-85; KOWZAN, Tadeusz, «Identidad del personaje teatral: del anonimato a la autorreferencia», Theatralia, $n^{\circ}$ 2: El personaje teatral. IIo Congreso Internacional de Teoría del Teatro, Vigo, Universidad de Vigo, 1998, pp. 283-307; ídem, Literatura y espectáculo, Madrid, Taurus, 1992; SPANG, Kurt, Teoría del drama: lectura y análisis de la obra teatral, Pamplona, Eunsa, Ediciones Universidad de Navarra, 1991. 
del jardín de un restaurante fuera de la ciudad. Henrique y Leonel, socialistas, están sentados a la mesa, a la izquierda —subrayémoslo- del escenario. La acotación indica que sobre ella se ven: «(...) duas garrafas de cerveja e respectivos copos mal cheios $(\ldots)^{63}$. Paralelamente, la tercera escena ve llegar, entre otros, a João y Antonio. Se trata de la primera vez que ambos personajes aparecen en escena. Las acotaciones los describen, respectivamente, como «tipo de operario vadio, bebado e desordeiro» y «o mesmo tipo de João, mas covarde e cinico» ${ }^{64}$. Se sitúan a la derecha, como nuevamente indica la acotación, pero la conversación nos deja entrever una diferencia más con el grupo formado por Henrique y Leonel:

«João - Estou como uma sêde levada dos diabos! E a caminhada abriu-me o apetite...

Antonio - (...) E a mim a mesma coisa... Também só mandas-te trazer vinho...» ${ }^{65}$

La oposición en el consumo de las bebidas alcohólicas, en este caso entre la cerveza, considerada más refinada, frente al vino, vulgar y basto, es solo una más en la complicada y sutil red de oposiciones maniqueas que preside la construcción de los personajes. A lo largo de la obra los espectadores verán cómo João y António desprecian la asistencia al centro obrero, desdeñan propuestas de carácter ideológico-partidario, como asistir al mitin, y verán al primero asesinar a su esposa con una navaja.

\subsection{La dirección escénica: las acotaciones}

Como hemos visto las acotaciones marcan pocas directrices en lo que respecta a la dirección de actores. Las indicaciones escenográficas son algo más precisas aunque la vaguedad sigue siendo la característica dominante. Sorprende la ausencia de naturaleza, subordinada a recintos como jardines o plazas de espacios geográficos urbanos. Estos, por su parte, suelen restringirse a dos: la fábrica y, sobre todo, los domicilios particulares. La adjetivación continúa siendo lacónica: «sala pobre», «sala decentemente mobilada», pero en algunos casos las indicaciones del autor nos permiten medir la dimensión exacta de la pobreza en la casa de un obrero. Al margen de la situación de las puertas, necesarias para la entrada y salida de los actores, la habitación que se nos describe en Amor Louco comporta el siguiente mobiliario:

63 SILVA, António Augusto da, A Amante, op. cit., 2º acto, p. 19.

64 Ídem, $2^{\circ}$ acto, scena III, p. 24.

65 Ibídem. 
«(...) uma caixa, um velho armário a um canto, uma mesa de pinho, duas cadeiras da mesma madeira, e alguns objectos próprios de casa de operário. Como a acção decorre de noite, um candeeiro em cima da mesa ilumina a cena»66.

En Duas Uniões Vitoriosas la decoración de las paredes está compuesta por «alguns cuadros alusivos á causa do proletariado»67. La tónica dominante es la presencia de libros, revistas o periódicos. No hay obra teatral que no insista en la presencia de estos objetos directamente relacionados con la cultura, situados en lugares bien visibles para el público como mesas o estantes. En Germinal se nos indican incluso los autores apropiados: «(...) Zólá, Grave, Malon, Tolstoi, Hamon, etc. ${ }^{68}$.

\subsection{La música}

La presencia de la música completa la dimensión pedagógica del teatro obrero. Dentro de la obra cumple dos funciones básicas. En primer lugar, se trataba de dar a conocer a los espectadores los himnos socialistas: el 1ํ de mayo, cantado en distintas escenas de O Capita ${ }^{69}$, y La Internacional, son los dos referenciados. Esta última aparece en obras más tardías, ya proclamada la República, como colofón final a Pedro, o Tecelão ${ }^{70}$, en $A$ Amante $^{71}$ y en Duas Uniões Vitoriosas, donde el autor incluye algunos versos del inicio y el estribillo ${ }^{72}$. Además, funciona como refuerzo del discurso doctrinal: en todos los casos suena en paralelo al debate ideológico, como apoyo emocional a la descripción de una imagen de injusticia social o indica el paso a la acción y la resolución final del conflicto.

\section{CONCLUSIONES}

Para los socialistas portugueses la prensa es un medio de comunicación que aúna información, análisis sociológico y difusión doctrinal ${ }^{73}$. En manos de historiadores es además una fuente privilegiada para el análisis del Movimiento Obrero

66 SILVA, António Augusto da, Amor Louco. Drama em 3 actos, original, Lisboa, Livraria Popular de Francisco Franco, 4ํe․, s.d., acto I.

67 DIAS, Jaime Ferreira, Duas Uniões Vitoriosas. Peça em 1 acto, Cova da Piedade, edição do autor, 1931 , p. 5.

68 PINTÉUS, Zé de, Germinal. Comedia de propaganda social em um acto, cêna, IV, en La cultura obrera en Portugal..., op. cit., p. 164.

69 SILVA, António Ernesto da, O Capital..., op. cit., acto segundo scena XII, p. 36; scena, XV, pp. 3840; scena XVII, pp. 43-44; y scena XIX, p. 45.

70 SILVA, António Augusto da, Pedro, o Tecelão..., op. cit., acto 3o, quinta cena, p. 71.

71 SILVA, António Augusto da, A Amante..., op. cit., 2ํacto, scena II, pp. 22-23.

72 DIAS, Jaime Ferreira, Duas Uniões Vitoriosas..., op. cit., scena IX, p. 19.

73 PERALTA GARCÍA, Beatriz, La cultura obrera en Portugal..., cit., cap. 3: «Los canales de difusión doctrinal», p. 69 y ss.; sobre la prensa obrera vid. también los trabajos de OLIVEIRA, César, «Imprensa operária no Portugal oitocentista de 1825 a 1905», Análise Social. Revista do Instituto de Ciências Sociais da Universidade de Lisboa, nº 39, Lisboa, 1973; ídem, Antologia da Imprensa Operária Portuguesa, 
Socialista dado el escaso volumen documental conservado, una dificultad apuntada por César Nogueira ${ }^{74}$ en 1932 y sentida por cuantos se han acercado al estudio de su historia socio-cultural. Es a los periódicos de las agrupaciones socialistas portugueses a quienes debemos la construcción del corpus dramático sobre el que se ha basado nuestro artículo. En efecto, la búsqueda de nuevas fuentes con las que suplir las carencias antes señaladas nos ha llevado a abordar la investigación desde un enfoque multidisciplinar. La literatura parece consolidarse así como un dominio cada vez más utilizado por lo historiadores, que han fijado su atención sobre todo en un género muy concreto, la novela ${ }^{75}$, y algo menos en la poesía y el teatro. Una vez más, en el caso portugués, este último se revela como un material imprescindible por su capacidad para aportar datos de diversa índole y naturaleza: doctrinal, lúdica, en el ámbito de la sociabilidad y de la cultura y las prácticas políticas... Nuestro trabajo ha intentado ofrecer un esquema de análisis del teatro partidario como fuente y, al mismo tiempo, mostrar su aplicación práctica para el estudio del Movimiento Obrero Socialista en Portugal.

Lisboa, UGT-União Geral dos Trabalhadores e Perspectiva e Realidades, Artes Gráficas, Ld ${ }^{\mathrm{a}}$, 1984; SÁ Vitor de, Roteiro da Imprensa Operária e Sindical, 1836-1986, Lisboa, Ed. Caminho, 1991.

74 NOGUEIRA, César, «A-propósito do aniversário do P.S.P.», Pensamento, Porto, ed. do Grupo Pensamento, №s 22-23, Janeiro-Fevereiro, 1932, pp. 523-524.

75 Para el caso del Movimiento Obrero Socialista español vid. los trabajos de BELLIDO NAVARRO, Pilar, Literatura e ideología en la prensa socialista (1885-1917), Sevilla, ed. Alfar, 1993; DE LUIS MARTín, Francisco, La cultura socialista en España, 1923-1930, Salamanca, ed. Universidad de Salamanca, 1993; ídem, Cincuenta años de cultura obrera en España, Madrid, ed. Pablo Iglesias, 1994; para el anarquismo LIVTAK, Lily, Musa Libertaria..., op. cit. 